\title{
Remote Education During a Nationwide Pandemic: Teaching and Learning (Dental Teachers and Students) During COVID-19
}

\author{
Jamshaid Mansoor $^{1}$ \\ ${ }^{1}$ Manchester Dental School, University of Manchester, Higher Cambridge Street, Manchester, M15 6FH, UK \\ Correspondence: Jamshaid Mansoor, Manchester Dental School, University of Manchester, Higher Cambridge \\ Street, Manchester, M15 6FH, UK. E-mail: jamshaid_manzoor@yahoo.co.uk
}

Received: May 24, 2020

Accepted: June 30, $2020 \quad$ Online Published: July 13, 2020

doi:10.5539/jel.v9n4p140

URL: https://doi.org/10.5539/jel.v9n4p140

\begin{abstract}
In the past few months, a viral pandemic has spread worldwide and continues to disrupt the everyday life of the whole population. The action plans: During this time, dentistry in the U.K. has suffered and the majority of dental care has ceased, with only some centres being able to offer emergency care for patients. Live education: The education of our dental students has been considered and modified to offer continuation of teaching and learning in a remote fashion, given the current conditions. Discussion: This format of teaching and learning has identified new possibilities relating to what is possible in dental education in the U.K., with the adequate organisation, dedication and flexibility that some of the electronic applications within remote education allow. Conclusion: The success of such a format lacks any published evidence, but the initial feedback from our dental students has been grossly positive, and; combined with such multiple benefits, may suggest a role for different formats for dental education in the future.
\end{abstract}

Keywords: COVID-19, Coronavirus, remote teaching, remote education, videoconferencing

\section{Clinical Relevance}

The COVID-19 pandemic has affected every branch of every tier within dentistry in the U.K. Special consideration of the next generation of dentists and dental care professionals is crucial. It is important to reassess and review how and if continuing education is possible for our dental students both academically and clinically.

\section{Objectives}

1) The alternative education methods required for dental students currently within a "lockdown" period during the COVID-19 pandemic will be discussed and described

2) Remote educational meetings have been the primary method of delivering teaching to dental students and the format of these will be outlined to readers

3) Dental student feedback will be highlighted, despite an absence of clinical research relating to the efficacy of such remote educational meetings

4) A discussion on whether there is merit in utilising the new formats of education delivery within dentistry

\section{Introduction: The Pandemic}

On Friday $13^{\text {th }}$ March 2020, the author delivered what was his own final day of teaching at University Manchester Dental Hospital until further notice. The dental students were informed and advised that day that it would most likely be the final day of teaching that can be delivered to them within Manchester University Dental Hospital. Although at that time, this was a mere prediction, clinical activity within Manchester University Dental Hospital had already been restricted and dentistry itself was already changing.

Reports have suggested that the first case of Coronavirus-19 (COVID-19) was identified in November 2019 in China, weeks before the authorities reported this new virus (The Guardian, 2020). In the early months of 2020, a "domino effect" has been seen worldwide, with every continent now suffering with COVID-19 cases amongst the population. Many countries have now implemented various measures to react to try to combat the established pandemic (European Comission, 2020). Coronaviruses are certain types of virus that effect the respiratory system, with COVID-19 being the latest untreatable variant. Symptoms include cough, fever, shortness of breath, muscles aches, sore throat and unexpected/unexplained loss of sense of smell. This type of virus has a 
characteristic "crown-like" appearance and has had the spill-over effect of being transmitted from animals to humans, and can now be spread from person to person and is air-bourne (John, 2020).

The U.K. has reacted to the pandemic with specific enforcement measures (GOV.UK, 2020). Dentistry itself has received various guidance from governing bodies, organisations and associations (NHS UK, 2020; General Dental Council, 2020; Btitish Dental Association, 2020; Care Quality Commission, 2020; Dental Protection, 2020; Faculty of General Dental Practitioners, 2020). Much of this guidance focuses on delivery of services in primary care, but not relating to services delivered in secondary care settings, or specifically, dental hospitals, where dental students are based. University Dental Hospitals have needed to create their own guidance, enforcements and instructions for their dental students, and Manchester University Dental Hospital is no different, but has needed to consider specifically the dental students. Manchester University Dental Hospital has created an action plan to be able to continue to provide education for our dental students (Manchester University Dental Hospital, 2020).

\section{The Action Plans}

Dentistry is a degree that demands a mixture of a variety of scientific knowledge and understanding, accompanied with specialised clinical and practical skills. With such an obvious division between these elements within dentistry, it is clear to see that this is a different type of degree that absolutely requires dental students to be able to learn, practice and then be able to perform clinical, practical care as part of their learning. This also means that dental teachers need to be able to deliver this education in the appropriate way.

The identification and discussion of scientific, academic dentistry vs. clinical dentistry and application of Miller's Triangle is relevant to dental education (Taylor \& Grey, 2013). With the absence of face to face delivery of education from the dental teachers, to the students, it is now only possible to rely on remote teaching and learning, and some methods have been devised to be able to implement this (Manchester University Dental Hospital, 2020) via remote educational meetings.

The dental students' clinical skills and clinical dentistry of course will suffer during these unprecedented times, as dental teachers are not able to work with the dental students physically on dental patients, or even on tooth and gum models. One option may be to direct the dental students to webinars, educational videos and visual learning aids to assist them, certainly with the first couple of bases that formulate Miller's Triangle (Taylor \& Grey, 2013). The author does postulate that scientific, academic dentistry may be left unaffected or minimally effected by the enforcements of the pandemic, as the curriculum at Manchester University Dental Hospital focuses on an Enquiry-Based Learning (EBL) format, which requires the students to concentrate on self-directed learning.

EBL has a vital role within the way our undergraduate and postgraduate students learn within dental schools. EBL is a method of self-directed learning/research conducted and performed by the learner (University of Reading, 2019; University of Manchester, 2019). The current pandemic period allows students the opportunity to use the great amounts of free time that has become available, and some of this may be used to pursue this approach to learning.

To summarise EBL: the teacher within a particular session is seen more of a "facilitator", and guides the students, who will formulate their own lines of enquiry and questions, as well as encountering problems, which they must also solve; given the appropriate lines of enquiry and a "skeleton" of each learning objective from the "facilitator". This self-directed learning may continue in the absence of face to face contact, and any further enquiries or questions from students can easily be delivered via telecommunication, electronic e-mail or even social media.

\section{Live Education}

Videoconferencing has become established in the past two decades and is used in a broad range of learning purposes, although the systematic review by Lawson and co-authors (Sweet, Wilson, \& Pugsley, 2009) recognises barriers to effective teaching and learning remain. This is despite the increased robustness and ease-of-use of these technologies (Sweet, Wilson, \& Pugsley, 2009). Further research has assessed student opinion and their assessment of distance videoconferencing (Tony, Chris, Jenny, \& Adrian, 2010). The results of which would indicate that the teacher must appreciate the specifics and limitations of videoconferencing and also apply the correct methodology for students to perform equally well in a distanced setting (Tony, Chris, Jenny, \& Adrian, 2010).

One of the methods proposed to provide dental students with "live education"; substituting the face to face element, has been to promote the use of electronic/digital media applications on computers, "tablet" handheld 
devices and telephones. Some of these applications include Zoom ${ }^{\mathrm{TM}}$ and Facetime ${ }^{\mathrm{TM}}$. At Manchester University Dental Hospital have preferred to utilise the Zoom ${ }^{\mathrm{TM}}$ application, which offers users some highly useful features for both dental teachers and the dental students (Zoom, 2020):

- $\quad$ No financial cost

- Conference meetings/rooms inclusive of multiple users

- Screen sharing possible

- Calendar integration to arrange conferences and meetings

- $\quad$ File sharing

- $\quad$ Online chat

- $\quad$ HD video and audio

This application is favoured by the author and the basic version of the application does allow 40-minute conference or meeting to be held, before a restart is needed. Although there is no current research to assess or verify the efficacy of the Zoom ${ }^{\mathrm{TN}}$ application in relation to education (delivering teaching and facilitating learning), the University of San Francisco are already utilising it during the pandemic (Zoom, 2020), and the author has discussed some of the evidence within the literature relating to videoconferencing above. The author will discuss personal experience and the experiences of the allocated dental students - all of whom have completed an optional questionnaire relating to their learning via Zoom ${ }^{\mathrm{TM}}$ (see appendix one). The results of the questionnaire will be discussed further on within this piece.

The author has been organising some regular teaching sessions as remote educational meetings for the allocated dental students on a weekly basis. Each group of dental students participates in a single session per week, which usually lasts for 60-90 minutes. Within the teaching sessions, some participants will have both video and audio enabled, but all participants will have enabled audio, online chat room (within the meeting), file sharing and screen sharing. Prior to hosting these remote educational meetings, the author will e-mail all of the allocated students for the session, attach any relevant reading material, files or videos to view before the meetings begin, and also attach the remote educational meeting "invite" with the meeting identification number (ID) and password for the allocated students to be able to login, attend and access the remote educational meeting. The meetings are set-up by the author and as the host, and can only be begun and ended by the author also. The host will maintain full operational control of these teaching sessions. 


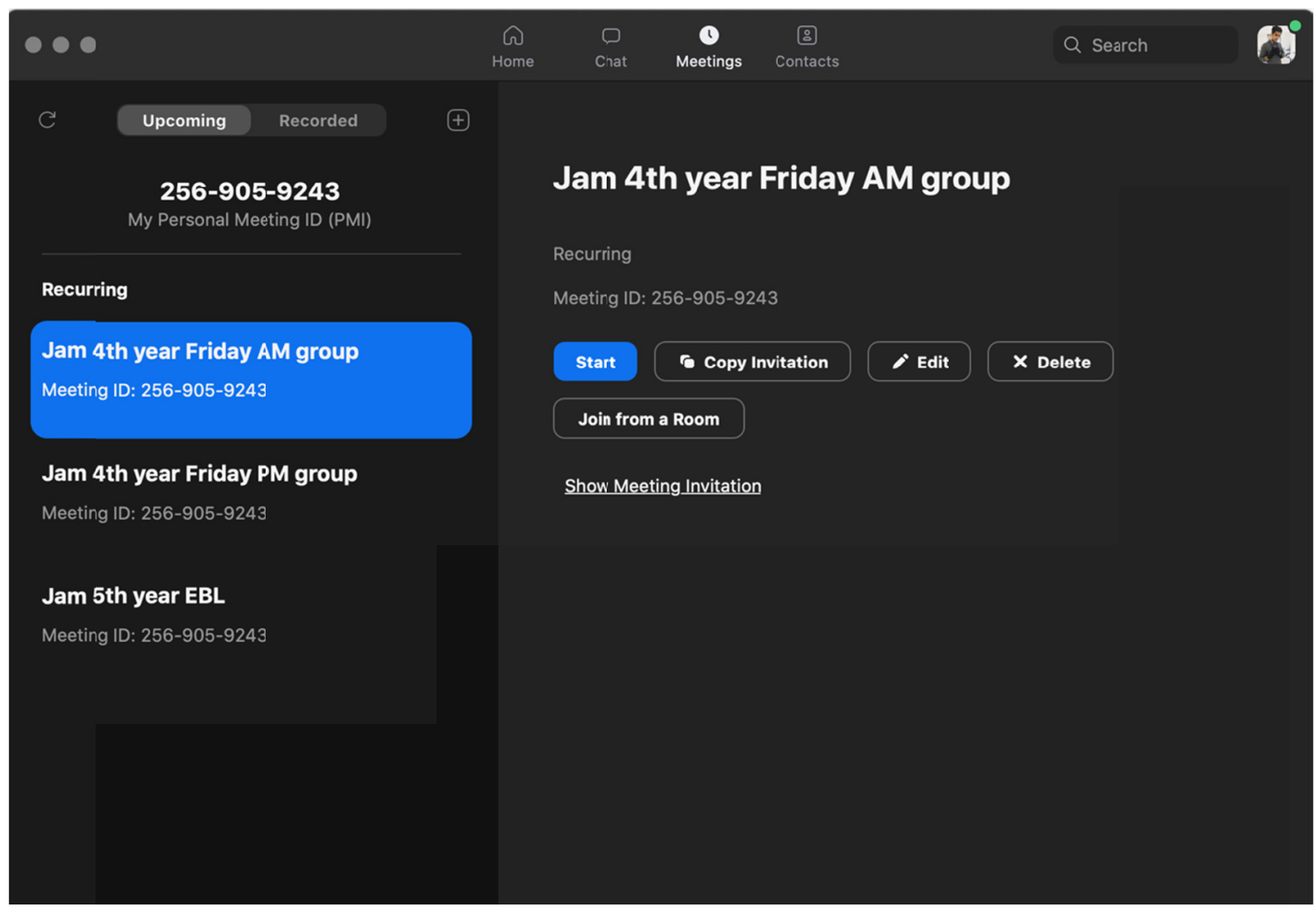

Figure 1. The layout and setup of the Zoom ${ }^{\mathrm{TM}}$ application (including calender) from the viewpoint of the author (host) to organise the remote educational meetings

The consensus from the author and other dental educators within Manchester University Dental Hospital in respect of the Zoom ${ }^{\mathrm{TM}}$ remote educational meetings is that they have been invaluable at being able to continue to deliver some dental education during the COVID-19 pandemic. The alternative of Facetime ${ }^{\mathrm{TM}}$ does not possess all over the useful features of the Zoom ${ }^{\mathrm{TM}}$ application. Other applications such as Adobe Connect ${ }^{\mathrm{TM}}$ require a recurring registration fee applicable, but does have the advantage of being able to provide the host with more control of their teaching sessions by incorporating features such as registration portal-where participants are required to "register" before they're given permission by the host to join the remote educational meeting (Adobe, 2020). Upgraded versions of Zoom ${ }^{\mathrm{TM}}$ do also offer this feature. Larger groups can join webinars, that many colleagues within dentistry are hosting at the moment; and the registration feature within Adobe Connect ${ }^{\mathrm{TM}}$ does allow the host of the webinar to account for the participants who join and to therefore be able to invoice them if the webinar is chargeable (Adobe, 2020). This particular software also has history within higher education and has been awarded with accolades recognisable for "E-Learning". Obviously, the cost implications mean that Manchester University Dental Hospital may not wish to select this application as it's choice to deliver the remote educational meetings. Given the cost-free available alternatives, that exhibit some excellent features to facilitate both teachers and learners, these may be more favourable, provided security and privacy issues are satisfied, which is a growing problem for these types of software, whatever their intended use (Koceska \& Koceska, 2013).

A negative the author has experienced within the basic Zoom ${ }^{\mathrm{TM}}$ application is the 40 -minute time restriction. Although this is easily overcome by restarting the remote educational meeting once you have been "timed out", it is still inconvenient and requires all participants to re-join the remote educational meeting once the host has restarted the meeting. The benefits, however, far outweigh this inconvenience, and it could be argued that the methodology of delivering this type of teaching and receiving this type of learning should be continued beyond the pandemic. As long as a pre-organised time for the remote educational meetings is agreed (or-if continued following the pandemic - arranged via the School of Dentistry), then this method to provide dental academic education would have additional value to the standard teaching and learning structure prior to the pandemic. The table below summarises the author's opinions of advantages and disadvantages of the remote educational meetings. 


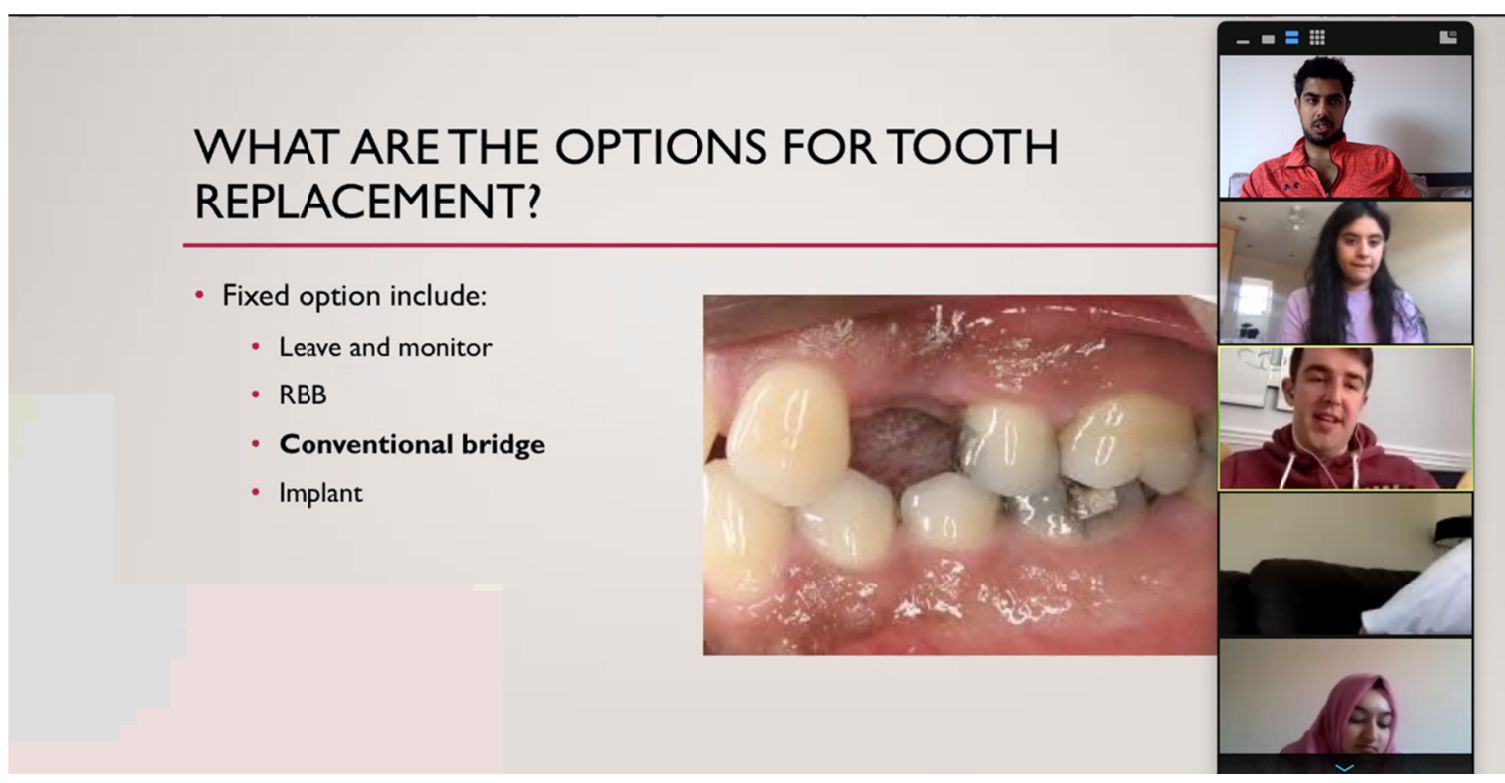

Figure 2. A remote educational meeting in progress, using the Zoom ${ }^{\mathrm{TM}}$ application

Table 1. Advantages and disadvantages of remote educational meetings (via the Zoom ${ }^{\mathrm{TM}}$ application)

\begin{tabular}{|c|c|}
\hline Advantages & Disadvantages \\
\hline $\begin{array}{l}\text { Host and participants may attend the remote educational } \\
\text { meetings from anywhere }\end{array}$ & $\begin{array}{l}\text { Restricted "time limit" on remote reaching sessions when using } \\
\text { basic version of the application }\end{array}$ \\
\hline Sessions may be recorded so can be revisited & $\begin{array}{l}\text { Remote educational meetings longer than } 40 \text {-minutes need to be } \\
\text { restarted by the host and require participants to re-join }\end{array}$ \\
\hline $\begin{array}{l}\text { Host and participants screen sharing is allowed and may be } \\
\text { enabled }\end{array}$ & $\begin{array}{l}\text { Limit of up to } 100 \text { participants within the remote educational } \\
\text { meetings when using basic version of the application. Sliding scale } \\
\text { of cost when wishing to include more participants }\end{array}$ \\
\hline $\begin{array}{l}\text { Host can control video and audio (e.g., all other participants can } \\
\text { be "muted" whilst one participant is speaking) }\end{array}$ & $\begin{array}{l}\text { Difficult to deliver clinical teaching as participants unable to } \\
\text { practice techniques without being in possession of the same } \\
\text { equipment/materials as the host and direct physical teaching not } \\
\text { possible }\end{array}$ \\
\hline Basic application is free of charge & $\begin{array}{l}\text { Lag delay sometimes possible and participants may speak at the } \\
\text { same time, but not be heard }\end{array}$ \\
\hline $\begin{array}{l}\text { Calendar integration will allow reminders to be set within } \\
\text { telephones/“tablets"/computers of prospective participants (and } \\
\text { also the host) }\end{array}$ & Does require some training before use \\
\hline $\begin{array}{l}\text { HD video and audio allows host and participants to be able to } \\
\text { view/hear one another wherever they may be }\end{array}$ & $\begin{array}{l}\text { Remote educational meeting ID and password may be shared } \\
\text { amongst others }\end{array}$ \\
\hline $\begin{array}{l}\text { The HD video and audio allows demonstration of clinical and } \\
\text { practical teaching and learning }\end{array}$ & \\
\hline $\begin{array}{l}\text { All participants will have the same viewing quality and audio } \\
\text { quality when host is demonstrating clinical/practical skills }\end{array}$ & \\
\hline $\begin{array}{l}\text { Less background noise and disruption from other student } \\
\text { cohorts within remote educational meetings }\end{array}$ & \\
\hline $\begin{array}{l}\text { Literature and teaching materials easily shareable and can be } \\
\text { provided to all participants at the same time, so no student is left } \\
\text { without the resource you wish to share with the group }\end{array}$ & \\
\hline Separate "chat room" function enabled, and possible also to & \\
\hline include a separate "Q and A" tab to enable participants to put & \\
\hline forward questions, as the remote educational meeting continues & \\
\hline - so allows these to be addressed at the end of the session & \\
\hline Simple to monitor attendance and punctuality & \\
\hline $\begin{array}{l}\text { Multiple electronic devices can be used simultaneously during } \\
\text { teaching sessions, to allow maximum acquisition of resources }\end{array}$ & \\
\hline
\end{tabular}




\section{Methodology}

40 anonymous closed questionnaires were completed by dental students at University of Manchester Dental School. These were made available by Google Forms ${ }^{\mathrm{TM}}$ to all participating students (who were randomly allocated under the author's teaching group at the beginning of the year) within the Dental School. Participants were made aware that the questionnaires were optional, and provided a link to these via an email sent to them from the administration staff. The results would be automatically submitted once completed, and the author would be sent an email to be made aware that a questionnaire had been completed. Participants were free to complete the questionnaires in private, in their own time. This was double-blinded as the participants do not identify themselves on their form, and also, they do not know for whom this research and data is being gathered for.

Although this data has been assimilated, used and interpreted, the author would like to emphasise that this quantitative method of acquiring research data will only provide restricted information; as the thoughts, feelings and perceptions of participants cannot be effectively transmitted and demonstrated with closed-question acquisition of data. Therefore, the analysis of the data and the results and conclusion from it should be interpreted with caution and further research is certainly required. More robust methods with would ideally combine the techniques to acquire qualitative and quantitative data, and would be desirable and needed within further research to provide more complete and accurate data for analysis and interpretation.

\section{Results}

The results of the student questionnaire are pretty conclusive. Of the author's 40 allocated dental students, each student responded. It is to be noted that these students were randomly allocated to the author at the beginning of the academic year in September 2019. The opinions of students allocated to other dental teachers may differ, and it is important to consider the outcome of feedback may be resultant of the chosen dental teacher, rather than the remote educational meetings. The author is also acutely aware that there are differing "generation gaps" across selected dental teacher pairings with allocated dental students. For example, an age difference less than eight years exists between the author and his own allocated dental students. For some pairings this is more than triple!

The full results of the questionnaire are shown in appendix two. Some of the simple points of discussion to begin with are the results demonstrating none of the students questioned believe that the remote educational meetings were better than their standard dental education and in fact all students reported they were worse. This is likely to be associated with the lack of ability to be able to fulfil their clinical skills and development in the absence of physical clinical teaching and learning practically. All questioned students also believed there was nothing their tutor could do further to facilitate their learning during the pandemic. This may be because the enforcements of the pandemic largely restrict the ability of dental teachers to be able to "do" much as the population are all restricted to government's enforced "lockdown rules" (GOV.UK, 2020).

Interestingly, when reviewing the results of the questionnaires, the same respondents $(10 \%)$ who had answered "no" to the first question also reported not enjoying the Zoom ${ }^{\mathrm{TM}}$ meetings and also disagreed that the remote educational meetings enhanced their ability to access, share and discuss electronic resources (question five). It has also been noted by the author that a small minority of the 40 students do not attend the remote educational meetings, and the pattern of absence is consistent with some individuals. $90 \%$ of the allocated dental students have stated they find the remote educational meetings beneficial academically, and report to enjoy them. This demonstrates a high satisfaction amongst the respondents. Surprisingly, almost half of the responding students reported that the remote educational meetings have been beneficial clinically, despite the lack of face to face contact or the ability to learn physically with their dental teacher. Over half of the allocated dental students actually revealed they found the remote educational meetings "better" than the normal delivery of their academic dental education. This would support the author's view that it could be considered continuing and developing these remote educational meetings beyond the exit of the COVID-19 pandemic. Finally, to note, $80 \%$ of allocated dental students agree with the author's opinion that the ability to utilise resources has been enhanced by the remote educational meetings.

\section{Discussion}

It is the author's genuine belief that this format of teaching and learning will still have a welcomed place within the curriculum, even following the COVID-19 pandemic. These views are demonstrated by the table above, which highlights the numerous multiple benefits of that this format of education offers.

Perry demonstrated that student learning is influenced by relationships with peers, their views of themselves and interactions, not merely the content of the curriculum and therefore concluded the learning process is enhanced by these factors (Perry, 1999). Remote educational meetings certainly provide a dynamic alternative when 
considering relationships with peers and interactions. Some research has also demonstrated that students in higher education now play an integral part determining the content and objectives of their course (Knowles et al., 2005). This is of great relevance to the dentistry degree — our students have the opportunity on a weekly basis (at least) to feedback their opinions on the remote educational meetings. Some have already done so via the questionnaire that was completed. Other research has also focussed on the opinions and views of students in relation to remote educational meetings and does highlight some key finding and issues (Gillies, 2008).

Some previous research assessing the appropriateness, methodology and organisation of remote educational meetings suggests that they require a greater pre-organisation effort and perhaps more relevantly and importantly in relation to this article is that it has also been concluded that the best results using this technology are gained when it is completely necessary and extremely useful (Trentin \& Beningo, 1997). These are such times where the author would deem the situation that the coronavirus pandemic has left higher dental education in would make the remote educational meetings both completely necessary and useful. Previous research also comments on the fact that this technique of delivering and receiving education encourages independent group work, rather than all individual assessments (Abbott, 1994). This supports the method of the author's own sessions (see Figures 2 and 3 ), whereby the author's allocated students are actively participating in independent group work by presenting different dental topics to the author and their peers. The remote educational meetings allow for the presentations to take place with the presenter selected as the "host" and able to "mute" the other remote educational meeting participants whilst they perform their presentation to the group. The group of students is then able to discuss the presentation and selected desired topics in depth with all electronic resources at hand with appropriate internet access.

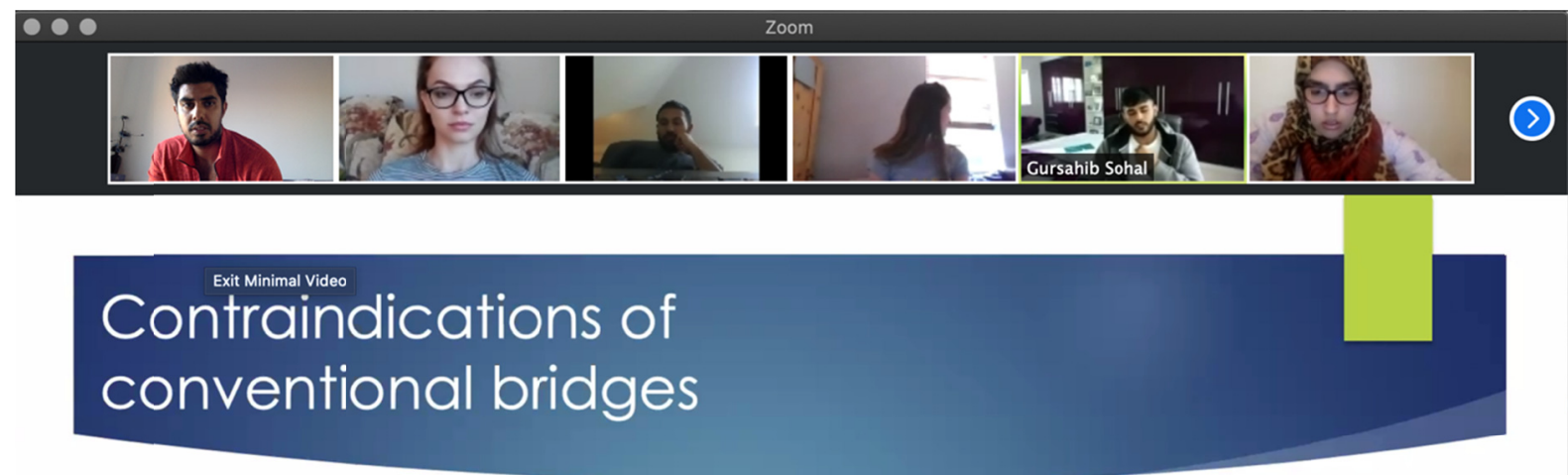

1. Periodontal disease

2. Poor oral hygiene

3. Long edentulous spans

4. Deep overbite

5. Parafunction

6. Existing over-eruption of opposing teeth

7. Difficult to repair

Figure 3. A remote educational meeting in progress, using the $\mathrm{Zoom}^{\mathrm{TM}}$ application. Note the change in layout that is possible and has been executed compared with Figure 2

Bruffee (1995) and co-authors concluded that learning is socially based and culturally determined. This can further support the application of the remote educational meetings, and may even promote a sense of comradery between peers assigned to each allocated student group and play to the strengths of the culture of a more digitally-driven generation (the majority of the students within the Manchester University Dental Hospital are now "generation Z") (Bruffee, 1995). The characteristics of "generation Z" include being at ease and 
synonymous with digital media, the internet and social platforms (BBC Bitesize, 2020).

The opportunity to hold these sessions is superior to ordinary face to face settings as they can be simply arranged electronically and conducted within the desired location of participants (including the participants' own place of residence). Usually this benefit promotes the additional convenience that time flexibility is more accepted - in particular because participants may find a greater opportunity to attend the remote educational meetings at their desired leisure.

The educational literature is now aware of the undoubted benefits of digital media and technology to aid education, but still remains tentative in its ability to theorise these (Savin-Baden, 2008), particularly in the form of learning spaces - there is a need to recognise and promote new learning spaces in academia (BBC Bitesize, 2020). Will the remote educational meetings become a recognised learning space for students now, or in the near future? Furthermore, Sieber and Briggs (2008) also stated the importance that "institutions need to ensure that they provide additional means for inclusive student use of shared resources on the web".

It would appear there is certainly room to incorporate the format of remote educational meetings to assist with dental education, however the very raw and current views of dental teachers and students must be interpreted with caution. The initial concerns are apparent from within the results of the questionnaire. Half of students report deficiencies with clinical education via remote educational meetings. This problem has been reported already, within the first two months following closure of University Manchester Dental Hospital. It would be interesting to review these opinions again in the future, if the current government enforcements continued for a period of time, and also to gauge the opinion of the dental teachers also, as this initial phase of positive feedback and opinion may change, especially given the complete inability to deliver/receive any practical, physical education that forms such a large part of the clinical education for dental students.

\section{Conclusion}

The flexibility, stimulation, adaptability, social power and workability of the remote educational meetings has provided some benefits to stabilise and continue to deliver some high-quality education for dental students. Although there is a lack of evidence and research to support this view, the feedback from questioned dental students themselves has been extremely positive. The ability of "generation Z" students to be able to readily utilise the developments in technology, applications and electronic features would seem to make them ideal candidates to be able to maximise the effectiveness of the equipment and materials available and used to assist the success of the remote educational meetings, given adequate support (if needed). Although these sessions lack the irreplaceable physical teaching and learning of clinical skills and development, there are still some elements of clinical and practical dentistry that can be taught and learned via the remote educational meetings (such as the promotion of video and media content). It would seem cost implications are minimal and ergonomically these sessions would not require strenuous and difficult setup. Future development of the remote educational meetings may focus on concentration around improving practical/clinical teaching and learning and trying to utilise methods to deliver the sessions to larger groups. The benefit of being able to record such sessions is fantastic feature to allow revision and refreshment of acquired knowledge and skills.

Although the spot light of this format of education has landed purely due to the commencement of the enforcements by the U.K. government in response to the COVID-19 pandemic, it would appear the efficacy, satisfaction and benefits of such a format would be highly commendable and may be of great use in the future of dental education.

\section{References}

Abbott, L. et al. (1994). The Application of Videoconferencing to the Advancement of Independent Group Learning for Professional Development. Educational and Training Technology International, 31(2), 85-92. https://doi.org/10.1080/0954730940310201

Adobe. (2020). Adobe Go Virtual. San Jose, California, U.S.A. Retrieved April 20, 2020, from https://www.adobe.com/products/adobeconnect.html

BBC Bitesize. (2020). Millenials, baby boomers, or Gen Z: which one are you and what does it mean? London, U.K. Retrieved April 23, 2020, from https://www.bbc.co.uk/bitesize/articles/zf8j92p

British Dental Association. (2020). Live updates: coronavirus and dentistry. London, U.K. Retrieved April 23, 2020, from https://bda.org/advice/Coronavirus/Pages/latest-updates.aspx

Bruffee, K. A. (1995). Collaborative learning: higher education, interdependence, and authority of knowledge, Batimore and London. The John Hopkins University Press. https://doi.org/10.2307/358879 
Care Quality Commission. (2020). Coronavirus (Covid-19) pandemic: information for providers. London, U.K. Retrieved April 20, 2020, from https://www.cqc.org.uk/guidance-providers/all-services/coronavirus-covid-19-pandemic-information-provid ers

Dental Protection. (2020). Coronavirus guidance for practice principals. London, U.K. Retrieved March 18, from https://www.dentalprotection.org/uk/articles/coronavirus-guidance-for-practice-principals

European Comission. (2020). EU global response to COVID-19. Brussels, Belgium. Retrieved April 14, 2020, from https://ec.europa.eu/international-partnerships/topics/eu-global-response-covid-19_en

Faculty of General Dental Practitioners. (2020). Coronavirus: advice for primary dental care. London, U.K. Retrieved February 28, 2020, from https://www.fgdp.org.uk/news/coronavirus-advice-primary-dental-care

General Dental Council. (2020). Covid-19 latest information. London, U.K. Retrieved March 23, 2020, from https://www.gdc-uk.org/information-standards-guidance/covid-19/covid-19-latest-information

Gillies, D. (2008). Student perspectives on videoconferencing in teacher education at a distance. Distance Education, 29(1), 107-118. https://doi.org/10.1080/01587910802004878

GOV.UK. (2020). Coronavirus (COVID-19): what you need to do. London, U.K. Retrieved April 20, 2020, from https://www.gov.uk/coronavirus

John Hopkins Medicine. (2020). What is Coronavirus? Baltimore, Maryland, U.S.A. Retrieved April 23, 2020, from https://www.hopkinsmedicine.org/health/conditions-and-diseases/coronavirus

Knowles, M. S., HoltonIII, E. F. et al. (2005). The adult learner: the definitive classic in adult education and human resource development. Burlington MA: Elsevier.

Koceska, S., \& Koceska N. (2013). Challenges of videoconferencing distance education-a student perspective. International Journal of Information, Business and Management, 5(2), 274-281

Manchester University Dental Hospital. (2020). Online and offline delivery of teaching (pp. 1-6). School of Dentistry.

Mansoor, J. (2020). Do dental students believe their teachers should possess tailored qualifications adherent to either clinical educational proficiency or scientific educational proficiency, in parallelism to these fields in which they are selected to teach? PG(Cert) in Higher Education (module 3, pp. 1-12).

McGraw, G. (2004). Software security. IEEE Security \& Privacy, 2(2), 80-83. https://doi.org/10.1109/MSECP.2004.1281254

NHS UK. (2020). Dental Practice. London, U.K. Retrieved April 15, 2020, from https://www.england.nhs.uk/coronavirus/primary-care/dental-practice/

Perry, W. G. (1999). Forms of ethical and intellectual development in the College Years: a scheme. San Francisco: Jossey-Bass Wiley imprint.

Savin-Baden, M. (2008). Learning spaces: creating opportunities for knowledge creation in academic life, 'Learning spaces, agency and notions of improvement: what influences thinking and practices about teaching and learning in higher education? An interpretive meta-ethnography'. London Review of Education, 6(3), 211-237. https://doi.org/10.1080/14748460802489355

Sieber, V., Briggs, A. et al. (2008). Student managed eLearning; ePortfolios, identity and personalised learning in healthcare education. 28 February 2008 Newcastle.

Sweet, J., Wilson, J., \& Pugsley, L. (2009). Educational innovations for dentistry. BDJ, 6(1), 29-34. https://doi.org/10.1038/sj.bdj.2008.1123

Taylor, C., Grey, N., \& Satterthwaite, J. D. (2013). Assessing the clinical skills of dental students: A review of the literature. Journal of Education and Learning, 2(1), 20-34. https://doi.org/10.5539/jel.v2n1p20

The Guardian. (2020). The first covid-19 case. London, U.K. Retrieved March 19, 2020, from https://www.theguardian.com/world/2020/mar/13/first-covid-19-case-happened-in-november-china-gover nment-records-show-report

Tony, L., Chris, C., Jenny, G., \& Adrian, C. - H. (2010). Images of the future for education? Videoconferencing: a literature review. Technology, Pedagogy and Education, 19(3), 295-314. https://doi.org/10.1080/1475939X.2010.513761 
Trentin, G., \& Beningo, V. (1997). Educational Technology. JSTOR, 37(5), 32-39.

University of Manchester. (2019). What is enquiry-based learning? University of Manchester, U.K. Retrieved December 17, 2019, from http://www.ceebl.manchester.ac.uk/ebl/

University of Reading. (2019). What is enquiry-based learning? University of Reading, U.K. Retrieved December 17, 2019, from https://www.reading.ac.uk/cetl-aurs/LinkingTeachingandResearch/Enquiry-BasedLearning/What_is_Enquir y_Based_Learning_(EBL).aspx

Zoom. (2020). Zoom for education. San Jose, California, U.S.A. Retrieved April 20, 2020, from https://zoom.us/education

\section{Appendix A}

\section{Zoom $^{\text {TM }}$ questionnaire provided to dental students}

\section{Remote education during a nationwide pandemic: education experience of dental students}

As you are aware, in recent weeks, Manchester University Dental Hospital has had to suspend face to face teaching as per government enforcement due to the Coronavirus (COVID-19) pandemic. During these times, you have continued to receive remote dental education via electronic applications, most notably: Zoom ${ }^{\mathrm{TM}}$. I would be very grateful if you would kindly complete the following questionnaire, underlining your desired response, then returning it to: Jamshaid_manzoor@yahoo.co.uk

1) Have you found the Zoom ${ }^{\mathrm{TM}}$ educational meetings useful and beneficial academically? Yes No

2) Have you found the Zoom ${ }^{\mathrm{TM}}$ educational meetings useful and beneficial clinically? Yes No

3) Academically: compared with the normal delivery of your dental education, you have found the Zoom ${ }^{\mathrm{TM}}$ educational meetings:
Better
Worse
No difference

4) Clinically: compared with the normal delivery of your dental education, you have found the Zoom ${ }^{\mathrm{TM}}$ educational meetings:
Better
Worse
No difference

5) The Zoom ${ }^{\mathrm{TM}}$ educational meetings have enhanced your ability to access, share and discuss electronic resources with your dental educator and your peers:
Agree
Disagree
Neither agree nor disagree

6) You enjoy the format of your Zoom ${ }^{\mathrm{TM}}$ educational meetings with your dental educator:
Agree
Disagree
Neither agree nor disagree

7) Do you believe your dental educator could be doing more to facilitate your learning during the COVID-19 pandemic?

Yes

No

If "yes", please kindly leave some comments (if "no", leave blank):

\section{Appendix B}

\section{Zoom $^{\text {TM }}$ questionnaire provided to dental students - results}

Remote education during a nationwide pandemic: education experience of dental students

1) Have you found the Zoom ${ }^{\mathrm{TM}}$ educational meetings useful and beneficial academically?

$$
\text { Yes }(36 / 40)-90 \% \quad \text { No }(4 / 40)-10 \%
$$

2) Have you found the Zoom ${ }^{\mathrm{TM}}$ educational meetings useful and beneficial clinically?

$$
\text { Yes }(16 / 40)-40 \% \quad \text { No }(24 / 40)-60 \%
$$

3) Academically: compared with the normal delivery of your dental education, you have found the Zoom ${ }^{\mathrm{TM}}$ 
educational meetings:

Better $(24 / 40)-60 \% \quad$ Worse $(6 / 40)-15 \% \quad$ No difference $(10 / 40)-25 \%$

4) Clinically: compared with the normal delivery of your dental education, you have found the Zoom ${ }^{\mathrm{TM}}$ educational meetings:

Better $(0 / 40)-0 \% \quad$ Worse $(40 / 40)-100 \% \quad$ No difference $(0 / 40)-0 \%$

5) The Zoom ${ }^{\mathrm{TM}}$ educational meetings have enhanced your ability to access, share and discuss electronic resources with your dental educator and your peers:

Agree (32/40)-80\% Disagree $\quad(4 / 40)-10 \%$ Neither agree nor disagree (4/40) - 10\%

6) You enjoy the format of your $\mathrm{Zoom}^{\mathrm{TM}}$ educational meetings with your dental educator:

Agree (36/40)-90\% Disagree $\quad(4 / 40)-10 \%$ Neither agree nor disagree $(0 / 40)-0 \%$

7) Do you believe your dental educator could be doing more to facilitate your learning during the COVID-19 pandemic?

Yes $(0 / 40)-0 \% \quad$ No $(40 / 40)-100 \%$

If "yes", please kindly leave some comments (if "no", leave blank):

\section{Copyrights}

Copyright for this article is retained by the author, with first publication rights granted to the journal.

This is an open-access article distributed under the terms and conditions of the Creative Commons Attribution license (http://creativecommons.org/licenses/by/4.0/). 